\title{
Article
}

\section{Pd Single-Atom Sites on the Surface of PdAu Nanoparticles: A DFT-Based Topological Search for Suitable Compositions}

\author{
Mikhail Mamatkulov ${ }^{1}\left(\right.$, Ilya V. Yudanov ${ }^{1, *}\left(\mathbb{D}\right.$, Andrey V. Bukhtiyarov ${ }^{1}\left(\mathbb{D}\right.$ and Konstantin M. Neyman ${ }^{2,3, *(D)}$ \\ 1 Boreskov Institute of Catalysis of the Siberian Branch of the Russian Academy of Sciences (BIC SB RAS), \\ Novosibirsk 630090, Russia; mikhail@catalysis.ru (M.M.); avb@catalysis.ru (A.V.B.) \\ 2 Departament de Ciència de Materials i Química Física and Institut de Quimica Teòrica i Computacional, \\ Universitat de Barcelona, c/Martí i Franquès 1, 08028 Barcelona, Spain \\ 3 ICREA (Institució Catalana de Recerca i Estudis Avançats), Pg. Lluís Companys 23, 08010 Barcelona, Spain \\ * Correspondence: yudanov@catalysis.ru (I.V.Y.); konstantin.neyman@icrea.cat (K.M.N.)
}

check for

updates

Citation: Mamatkulov, M.; Yudanov, I.V.; Bukhtiyarov, A.V.; Neyman, K.M. Pd Single-Atom Sites on the Surface of PdAu Nanoparticles: A DFT-Based Topological Search for Suitable Compositions. Nanomaterials 2021, 11, 122. https://doi.org/10.3390/ nano11010122

Received: 11 December 2020 Accepted: 4 January 2021 Published: 7 January 2021

Publisher's Note: MDPI stays neutral with regard to jurisdictional clai$\mathrm{ms}$ in published maps and institutional affiliations.

Copyright: $\odot 2021$ by the authors. Licensee MDPI, Basel, Switzerland. This article is an open access article distributed under the terms and conditions of the Creative Commons Attribution (CC BY) license (https:// creativecommons.org/licenses/by/ $4.0 /)$.

\begin{abstract}
Structure of model bimetallic PdAu nanoparticles is analyzed aiming to find Pd:Au ratios optimal for existence of Pd1 single-atom surface sites inside outer Au atomic shell. The analysis is performed using density-functional theory (DFT) calculations and topological approach based on DFT-parameterized topological energy expression. The number of the surface Pd1 sites in the absence of adsorbates is calculated as a function of Pd concentration inside the particles. At low $\mathrm{Pd}$ contents none of the Pd atoms emerge on the surface in the lowest-energy chemical orderings. However, surface Pd1 sites become stable, when Pd content inside a Pd-Au particle reaches ca. 60\%. Further Pd content increase up to almost pure Pd core is accompanied by increased concentration of surface Pd atoms, mostly as Pd1 sites, although larger Pd ensembles as dimers and linear trimers are formed as well. Analysis of the chemical orderings inside PdAu nanoparticles at different Pd contents revealed that enrichment of the subsurface shell by Pd with predominant occupation of its edge positions precedes emergence of Pd surface species.
\end{abstract}

Keywords: bimetallic nanoparticles; chemical ordering; density functional calculations; single-atom alloy catalysts

\section{Introduction}

Metal nanoalloys constitute a modern class of materials important for many applications [1]. In catalysis, bimetallic nanosystems are often superior by their properties to the monometallic counterparts. For instance, there is a growing interest in a special class of bimetallic nanosystems, where a catalytically highly active metal, e.g., Pd or Pt, is distributed on the surface at sufficiently low concentration in the form of individual atoms embedded in the environment of a relatively inert metal, such as Au, Ag, or Cu [2-7]. These combinations allow solving a well-known problem whereby excellent reactivity of active metals often causes poor selectivity. Since the pioneering publications of Goodman and co-workers $[2,3] \mathrm{PdAu}$ nanoalloys are among the targets of active studies in the rapidly developing research field known now as single-atom catalysis $[8,9]$, in particular in one of its branches dealing with single-atom alloys [10,11].

Gold-palladium system is a good example of a miscible alloy in the bulk. However, a lower surface energy of gold along with larger size of its atoms than palladium ones leads to surface enrichment by this element in thermodynamic equilibrium [12]. Under reaction conditions the surface thermodynamics may be alternated due to the stronger interaction of Pd with adsorbed species giving rise to surface segregation of Pd [13,14]. Since the chemical functionality of bimetallic nanoparticles (NPs) is intimately linked to their surface, a detailed understanding of nanoparticle architecture and control of its eventual changes under operating conditions are crucial for the rational design of nanosized materials with optimal catalytic performance [8,12]. 
Due to the complexity of bimetallic nanosystems the successful strategy to characterize their properties combines experimental and theoretical techniques $[14,15]$. At the computational level, density-functional theory (DFT) calculations provide quite reliable potential energies for metal nanosystems including bimetallic ones [16]. However, being efficient for nanosystems containing up to several hundred metal atoms, the DFT approach remains very computer-demanding for NPs comprising $>10^{3}$ atoms. The scaling techniques based on DFT calculations of smaller NPs are available to reach larger size range for monometallic particles [17,18]. Besides the usual DFT modeling, ab initio molecular dynamics is a reasonable approach, although still quite expensive for routine applications to nanoalloy particles at sizes in the scalable regime. A promising approach for explicit simulations of bimetallic NPs employs simplified Hamiltonians, such as that of the embedded-atom method (EAM) parameterized on DFT data [19]. Another modeling approach relies on a DFT-parameterized topological energy expression (TOP method) [20,21] broadly applicable to bimetallic (vide infra) and other binary nanocrystals. The TOP expressions enable comprehensively exploring configurational space of locations (homotops) of two types metal atoms in different crystalline positions of bimetallic NPs with given nuclearity and morphology by Monte-Carlo (MC) minimization. Minimum-energy homotop in the explored configurational space provides thermodynamically stable distribution of two types of metal atoms over the lattice of the bimetallic NP under scrutiny, i.e., its equilibrium chemical ordering. Energies of other arbitrary chemical orderings can be also evaluated within the same approach [20].

Despite extensive studies of PdAu NPs by various theoretical approaches [19-26] there are still open questions on their equilibrium structure, even in the absence of adsorbates (under vacuum conditions). In particular, there is only a limited knowledge on the conditions for the presence of $\mathrm{Pd}$ on the surface, in terms of particle size and composition. If the content of $\mathrm{Pd}$ is small enough as, for instance, in $\mathrm{Pd}_{0.25} \mathrm{Au}_{0.75}$ composition, the outer shell totally consists of $\mathrm{Au}$ [19]. On the other hand, the compositions with a high $\mathrm{Pd}: \mathrm{Au}$ ratio $\mathrm{Pd}_{0.75} \mathrm{Au}_{0.25}$ exhibit significant presence of Pd monomers, small ensembles, and islands even at low temperatures in the NPs with a wide size range, from $~ 100$ to 5000 atoms [19]. For intermediate compositions, such as $\mathrm{Pd}_{0.5} \mathrm{Au}_{0.5}$, the situation is less clear: While for small NPs of $\sim 100$ atoms their interior is too small to accommodate all available Pd atoms, whose excess has to be distributed on the surface [21], for NPs larger than 1000 atoms the results provided by different approaches are slightly controversial, reporting either gold-coated NPs [21] or alloyed surfaces with substantial fraction of Pd species [19].

The present DFT and TOP study is performed with the goal to determine the conditions for appearance of single Pd atoms (monomers) on the surface of PdAu NPs. In contrast to the previous theoretical studies $[19,21]$ based on the limited number of compositions, here a higher resolution with respect to $\mathrm{Pd}$ :Au ratio is explored, starting from a very low $\mathrm{Pd}$ fraction and gradually increasing it to about $\mathrm{Pd}_{0.5} \mathrm{Au}_{0.5}$. First, truncatedoctahedral $\mathrm{NP}_{201}$ models with the fixed nuclearity and shape were addressed to study how distribution of the metal components within the NP-in the inner part and in the surface shell—changes with increasing Pd:Au ratio. The TOP technique was used to select the most stable configurations (homotops) applying DFT calculations to determine relative stability of these homotops. Further, the main findings were expanded to isomorphic NPs with higher nuclearity to find the $\mathrm{Pd}$ :Au ratio corresponding to the early appearance of $\mathrm{Pd}$ surface species on the particles with a given size. The ordered structures formed in the inner parts of these larger NPs at various Pd:Au ratios were also investigated.

\section{Computational Details and Modeling Approach}

DFT calculations were performed with the VASP code $[27,28]$, employing PAW core potentials $[29,30]$, and a gradient-corrected exchange-correlation functional by Perdew, Becke, and Ernzerhof (PBE) [31,32]. As in our previous work [14], for the determination of energetic descriptors from the topological expression (see Equation (1) below) a cutoff energy $250.9 \mathrm{eV}$ was applied using the unit cell size $25 \times 25 \times 25 \AA^{3}$ allowing a 
sufficient separation of $8 \AA[33,34]$ between periodically repeated PdAu NPs composed of locally relaxed 201 atoms. As shown elsewhere [20,21], the usage of such somewhat less precise than common computational parameters in series of DFT calculations of metal NPs provides sufficient accuracy for determining the TOP energetic descriptors. In all calculations only $\Gamma$-point was used for the Brillouin zone sampling.

A modeling approach based on DFT calculations of highly symmetric particles [35-37] was applied to simulate the structure of bimetallic NPs. The main part of the present study is done with a truncated octahedral model $\mathrm{NP}_{201}$ at various $\mathrm{Pd}_{\mathrm{x}} \mathrm{Au}_{201-\mathrm{x}}$ compositions. This model, $\mathrm{NP}_{201}$, is small enough for extensive DFT calculations involving many $\mathrm{Pd}: \mathrm{Au}$ configurations, each represented by a number of different topological arrangements (homotops) of Pd and $\mathrm{Au}$ atoms. On the other hand, such 1-2 nm large model NPs comprising few hundred atoms are already beyond the size range, where the quantum effects play role determining strong variation of properties [18]. Respectively, these model NPs belong to the scalable size range $[18,35,38]$, which allows to extrapolate their properties to properties of NPs with $10^{3}-10^{4}$ atoms corresponding to operational experimental model catalysts (3-7 nm) [13]. Thus, the DFT parameterization of the TOP method [20] obtained for the 201-atomic NPs $\mathrm{Pd}_{\mathrm{x}} \mathrm{Au}_{201-\mathrm{x}}$ is applied to study the distribution of $\mathrm{Pd}$ and $\mathrm{Au}$ atoms in the isomorphic 586- and 1289-atomic models $\mathrm{Pd}_{\mathrm{x}} \mathrm{Au}_{586-\mathrm{x}}$ and $\mathrm{Pd}_{\mathrm{x}} \mathrm{Au}_{1289-\mathrm{x}}$. This series of the truncated octahedrons is often referred to as Wulff particles, because the ratio of (111) and (100) facets in them obeys the Wulff construction conditions [14].

The topological energy expression defines the energy of each homotop as follows [20]:

$$
E_{T O P}=E_{0}+\varepsilon_{C O R N E R}^{A u} N_{C O R N E R}^{A u}+\varepsilon_{E D G E}^{A u} N_{E D G E}^{A u}+\varepsilon_{T E R R A C E}^{A u} N_{T E R R A C E}^{A u}+\varepsilon_{B O N D}^{A u-P d} N_{B O N D}^{A u-P d}
$$

where $E_{0}$ is a constant offset between the TOP and DFT energy scales that cancels in the targeting homotops energy differences, $N_{B O N D}^{A u-P d}$ is the number of Au-Pd bonds (nearestneighbor contacts) in the homotop; $N_{C O R N E R}^{A u}, N_{E D G E}^{A u}, N_{T E R R A C E}^{A u}$ are the numbers of $\mathrm{Au}$ atoms located in the corner, edge, and facet terrace positions on the surface of the homotop, respectively. The coefficients $\varepsilon_{Y}^{X}$ are energy descriptors representing energy contributions of either one Au-Pd bond or an Au atom located in the corresponding surface position of the NP to the total energy of the homotop, $E_{\mathrm{TOP}}$.

The DFT parameterization of Equation (1) for the $\mathrm{Pd}_{56} \mathrm{Au}_{145}$ composition of $\mathrm{NP}_{201}$ was obtained previously [14]. In the present work, the parameterization was performed for a number of other compositions of the $\mathrm{NP}_{201}$ model to account for the known dependence of the parameterization on the Pd:Au ratio [20]. The TOP energy descriptors obtained for the three compositions $\mathrm{Pd}_{56} \mathrm{Au}_{145}, \mathrm{Pd}_{79} \mathrm{Au}_{122}$, and $\mathrm{Pd}_{101} \mathrm{Au}_{100}$ with significantly different $\mathrm{Pd}: \mathrm{Au}$ ratios are given in Table 1. The parameterization of Equation (1) for each of these models was made according to the previously developed protocol [20] by fitting to several dozen of DFT energies for distinct homotops representing a variety of $\mathrm{Pd}$ and $\mathrm{Au}$ atoms distributions with a wide range of energies. The descriptors for intermediate compositions between $\mathrm{Pd}_{56} \mathrm{Au}_{145}$ and $\mathrm{Pd}_{79} \mathrm{Au}_{122}$ ones were obtained using linear approximations based on the calculated descriptors for these two compositions (see Supplementary Materials, Figure S1, Table S1). For each $\mathrm{Pd}_{\mathrm{x}} \mathrm{Au}_{201-\mathrm{x}}$ composition under scrutiny the MC-minimization of Equation (1) carried out to select a set of 20-40 low-lying homotops within the energy interval up to $0.5-0.8 \mathrm{eV}$ above the lowest state. Full structure optimization was performed to determine at the DFT level the (relative) energies of thus selected low-lying $\mathrm{NP}_{201}$ homotops (see energies and topological characteristics of studied homotops in Tables S2 and S3 of Supplementary Materials). In the chemical ordering calculations in the larger $\mathrm{NP}_{586}$ and $\mathrm{NP}_{1289}$ models the last verifying step by exceedingly demanding DFT calculations was omitted, fully relying on the $E_{\mathrm{TOP}}$ energies. Applications of this method [20,21] to various bimetallic NPs revealed that $E_{\mathrm{TOP}}$ expressions despite their simplicity are sufficient for very efficient determining reliable atomic distributions in the energetically most stable homotops, in good agreement with DFT data [14,15,39-44]. 
Table 1. Energy descriptors in the topological expression Equation (1) parameterized for various $\mathrm{Pd}_{\mathrm{x}} \mathrm{Au}_{201-\mathrm{x}}$ nanoparticle (NP) compositions along with accompanying data ${ }^{a}$.

\begin{tabular}{|c|c|c|c|}
\hline Parameter & $\mathrm{Pd}_{56} \mathrm{Au}_{145} b$ & $\mathbf{P d}_{79} \mathrm{Au}_{122}$ & $\mathbf{P d}_{101} \mathrm{Au}_{100}$ \\
\hline$E_{0}, \mathrm{eV}$ & -668.8974 & -707.8834 & -745.6012 \\
\hline$\varepsilon_{C O R N E R^{\prime}}^{A u} \mathrm{eV}$ & -0.3702 & -0.3854 & -0.4574 \\
\hline$\varepsilon_{E D G E}^{A u}, \mathrm{eV}$ & -0.3364 & -0.3452 & -0.3991 \\
\hline$\varepsilon_{T E R R A C E^{\prime}}^{A u}, \mathrm{eV}$ & -0.1922 & -0.2500 & -0.2872 \\
\hline$\varepsilon_{B O N D}^{A u-P d}, \mathrm{eV}$ & -0.0263 & -0.0248 & -0.0225 \\
\hline$\varepsilon_{T E R R A C E}^{A u} / \varepsilon_{B O N D}^{A u-P d}$ & 7.3 & 10.1 & 12.8 \\
\hline$N$ & 44 & 28 & 32 \\
\hline$\Delta E, \mathrm{eV}$ & 0.0000 & 0.0320 & 0.0000 \\
\hline$\delta, \mathrm{eV}$ & 0.0934 & 0.2225 & 0.2974 \\
\hline
\end{tabular}

$\bar{a} N$ is the number of DFT calculations performed to define Equation (1). The accuracy $\Delta E$ is the energy difference (within $E_{\mathrm{TOP}}$ data) between the lowest-energy homotop obtained in the DFT calculations and the lowest-energy homotop obtained in the TOP optimization. The precision $\delta$ is twice the residual standard deviation between $E_{\mathrm{TOP}}$ and $E_{\mathrm{DFT}}$ energies for arbitrarily chosen, 10-test low-energy homotops different from the homotops used to construct Equation (1). According to this definition relative TOP energies for each pair of homotops are within $\delta$ of the corresponding DFT energy differences with the probability $>95 \%$ [20]. ${ }^{b}$ Descriptors for $\mathrm{Pd}_{56} \mathrm{Au}_{145}$ are the same as in the previous publication [14].

\section{Results and Discussion}

\subsection{General Topological Analysis of Eventual Pd-Core/Au-Shell Segregation}

The topological energy expression, Equation (1), due to its simplicity, defines a rather straightforward and clear physical model of Pd/Au ordering in the nanoalloy. The following general trends can be derived from this expression. The three terms with negative values $\varepsilon_{Y}^{A u}$ reflect the fact that $\mathrm{Au}$ is more stable on the surface, as a consequence of its lower surface energy and larger size of atoms. The stability increases in the order terrace $<$ edge $<$ corner with the decrease of the coordination of the corresponding sites. On the other hand, the negative $\varepsilon_{B O N D}^{A u-P d}$ descriptor is responsible for the known miscibility of PdAu alloy. Thus, the ordering in the inner part of NP reaches energy minimum at the maximal number of $\mathrm{Pd}-\mathrm{Au}$ bonds, which is possible for a given $\mathrm{Pd} / \mathrm{Au}$ ratio in the volume confined by the surface shell of the NP.

Evidently, to bring Pd to the surface the term $\varepsilon_{T E R R A C E}^{A u}$ should be compensated by a number of additional $\mathrm{Pd}-\mathrm{Au}$ bonds formed via $\mathrm{Pd}-\mathrm{Au}$ atoms permutation between the inner part and the surface of NP. If Pd fraction is so low that all Pd atoms can be distributed in the inner volume of NP as monomers, every Pd atom can form, at most, $12 \mathrm{Pd}-\mathrm{Au}$ bonds. Pd atoms located in the surface shell may form, at most, nine Pd-Au bonds on terraces and even less on edges and corners, seven and six, respectively. Hence, as follows from Equation (1), the core-surface Pd-Au permutations for such low Pd concentrations are endothermic:

$$
\begin{aligned}
& \Delta E_{\text {CORE } \leftrightarrow \text { TERRACE }}=-\varepsilon_{\text {TERRACE }}^{A u}-3 \varepsilon_{B O N D}^{A u-P d} \\
& \triangle E_{C O R E \leftrightarrow E D G E}=-\varepsilon_{E D G E}^{A u}-5 \varepsilon_{B O N D}^{A u-P d} \\
& \triangle E_{\text {CORE } \leftrightarrow \text { CORNER }}=-\varepsilon_{C O R N E R}^{A u}-6 \varepsilon_{B O N D}^{A u-P d}
\end{aligned}
$$

Applying the values of the corresponding descriptors obtained for the $\operatorname{Pd}_{56} \mathrm{Au}_{145}$ composition, the permutation energy equals $0.27,0.47$, and $0.53 \mathrm{eV}$ for terrace, edge, and corner sites, respectively.

As an example of high $\mathrm{Pd}$ fraction, it is instructive to examine the stability of the ideal Pd-core/ Au-shell structure in terms of Equation (1). In this case, the Au atom on the surface (111) terrace forms three bonds with $\mathrm{Pd}$ of the subsurface shell. Therefore, according to Equation (1), the energy associated with the (111) terrace position occupied by $\mathrm{Au}$ atom is $\varepsilon_{T E R R A C E}^{A u}+3 \varepsilon_{B O N D}^{A u-P d}$. However, a permutation between Pd core and Au terrace creates additional Pd-Au bonds: Permuted $\mathrm{Au}$ atom in $\mathrm{Pd}$ inner core forms $12 \mathrm{Pd}-\mathrm{Au}$ bonds (if permutation involves deeper shells than the subsurface shell) and Pd atom in 
the surface shell forms six Pd-Au bonds with the neighboring Au atoms. Thus, the new homotop exhibits 15 more Pd-Au bonds than the ideal core/shell structure. Hence, the energy of such permutation $15 \varepsilon_{B O N D}^{A u-P d}-\varepsilon_{T E R R A C E}^{A u}$ suggests that the permutated homotop is more stable than the core/shell one. The ratio $\varepsilon_{T E R R A C E}^{A u} / \varepsilon_{B O N D}^{A u-P d}$ for $\mathrm{NP}_{201}$ (Table 1) grows with increasing $\mathrm{Pd}$ content from 7.3 in $\mathrm{Pd}_{56} \mathrm{Au}_{145}$ to 10.1 and 12.8 in $\mathrm{Pd}_{79} \mathrm{Au}_{122}$ and $\mathrm{Pd}_{101} \mathrm{Au}_{100}$, respectively. Since the composition $\mathrm{Pd}_{79} \mathrm{Au}_{122}$ exhibits a homotop with the ideal core/shell structure (the core of $\mathrm{NP}_{201}$ consists of 79 atoms), the descriptors obtained for this composition seem to be most appropriate for estimating the energetics of core/shell structures. This example shows that the ideal core/shell structure is not the most stable for $\mathrm{PdAu}$ NPs and surface Pd monomers become stable before the core is completely filled by $\mathrm{Pd}$. As shown in the following, the most stable $\mathrm{Pd}_{79} \mathrm{Au}_{122}$ homotops expose a considerable $\mathrm{Pd}$ fraction in the surface shell and surface $\mathrm{Pd}$ atoms become stable already at $\mathrm{Pd}: \mathrm{Au}$ ratios notably lower than that in $\operatorname{Pd}_{79} \mathrm{Au}_{122}$.

Notably, increased Pd content may produce descriptors even with $\varepsilon_{T E R R A C E}^{A u} / \varepsilon_{B O N D}^{A u-P d}>15$, as in the previous studies [20,21], where smaller models than $\mathrm{NP}_{201}$ were used for the parameterization of Equation (1). For instance, the descriptors for $\mathrm{Pd}_{70} \mathrm{Au}_{70}$ model [20] yield $\varepsilon_{T E R R A C E}^{A u} / \varepsilon_{B O N D}^{A u-P d}=15.4$. In the present work the composition $\operatorname{Pd}_{101} A_{100}$ also exhibits the value 12.8 rather close to the critical threshold of 15 , below which the homotops with ideal complete Au skins are predicted to become energetically competitive with homotops exposing isolated $\mathrm{Pd}$ atoms within such Au skins. At the compositions $\mathrm{Pd}_{70} \mathrm{Au}_{70}$ and $\mathrm{Pd}_{101} \mathrm{Au}_{100}$ the number of $\mathrm{Pd}$ atoms exceeds the size of the core of 44 atoms 1.6 times and of 79 atoms 1.3 times, respectively. Thus, application of such models for parameterizing Equation (1) would overestimate the stability of the core/shell segregation.

\subsection{Pd Surface Concentration as a Function of Pd Fraction in the Core}

Since the concentrations of two metal components on the surface and in the core (inside the outer atomic shell) of PdAu NP are different, we introduce the concentration/density of Pd atoms in the core as:

$$
\rho_{\text {core }}^{P d}=\frac{n_{\text {core }}^{P d}}{n_{\text {core }}}
$$

where $n_{\text {core }}^{P d}$ is the number of Pd atoms located in the core and $n_{\text {core }}$ is the total number of metal atoms in the core. For $\mathrm{NP}_{201} n_{\text {core }}$ equals 79 atoms (the outer shell consists of 122 atoms). The concentration (coverage) of $\mathrm{Pd}$ atoms on the (111) terraces is defined as:

$$
\theta_{\text {terrace }}^{\text {Pd }}=\frac{n_{\text {terrace }}^{\text {Pd }}}{n_{\text {terrace }}}
$$

where $n_{\text {terrace }}$ is the number of 9-coordinated atoms on the eight (111) facets, 56 for $\mathrm{NP}_{201}$, and $n_{\text {terrace }}^{P d}$ is the number of Pd atoms in these terrace positions. Occupation of (001) facets by Pd starts rather late compared to (111) facets and just one Pd1 monomer is obtained in present work on (001) facet in the lowest-energy homotop of $\mathrm{Pd}_{101} \mathrm{Au}_{100}$ composition. Therefore, $\theta_{\text {terrace }}^{P d}$ is defined here in terms of (111) terrace occupation.

To find out how the distribution of two metal components within the NP framework changes with $\mathrm{Pd}$ :Au ratio it is instructive to consider the $\mathrm{NP}_{201}$ model at various $\mathrm{Pd}_{\mathrm{x}} \mathrm{Au}_{201-\mathrm{x}}$ compositions using DFT data of the low-lying homotops selected by MC minimization of Equation (1) (Table 2). Figure 1 shows $\theta_{\text {terrace }}^{P d}$ as a function of $\rho_{\text {core }}^{P d}$. 


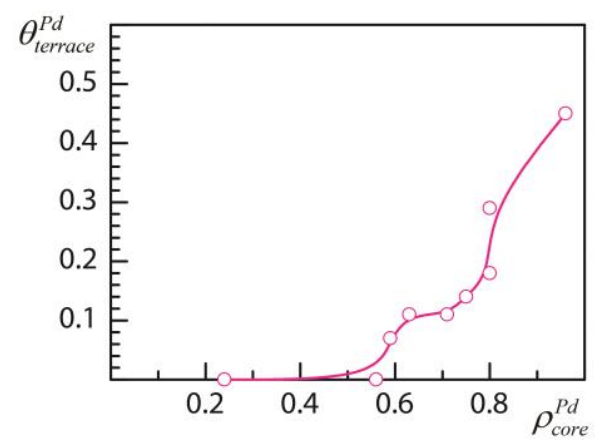

Figure 1. Concentration of Pd on the (111) terraces, $\theta_{\text {terrace }}^{P d}$, as a function of Pd concentration in the core of $\mathrm{NP}_{201}, \rho_{\text {core }}^{P d}$, calculated for different $\mathrm{Pd}_{\mathrm{x}} \mathrm{Au}_{201-\mathrm{x}}$ compositions (circles). See Table 2 for numerical data.

Table 2. Numbers of Pd atoms in the core, $n_{\text {core }}^{P d}$, and surface (111) terrace, $n_{\text {terrace, }}^{P d}$, sites of $\mathrm{NP}_{201}$ at various compositions $\mathrm{Pd}_{201-\mathrm{x}} \mathrm{Au}_{\mathrm{x}}$ and the corresponding Pd concentrations, $\rho_{\text {core }}^{P d}$ and $\theta_{\text {terrace }}^{P d}$.

\begin{tabular}{ccccc}
\hline & $\boldsymbol{n}_{\text {core }}^{\boldsymbol{P d}}$ & $\boldsymbol{\rho}_{\text {core }}^{\boldsymbol{P d}}$ & $\boldsymbol{n}_{\text {terrace }}^{\boldsymbol{P d}}$ & $\boldsymbol{\theta}_{\text {terrace }}^{\boldsymbol{P d}}$ \\
\hline $\mathrm{Pd}_{19} \mathrm{Au}_{182}$ & 19 & 0.24 & 0 & 0 \\
$\mathrm{Pd}_{44} \mathrm{Au}_{157}$ & 44 & 0.56 & 0 & 0 \\
$\mathrm{Pd}_{51} \mathrm{Au}_{150}$ & 48 & 0.60 & 3 & 0.05 \\
$\mathrm{Pd}_{56} \mathrm{Au}_{145}$ & 50 & 0.63 & 6 & 0.11 \\
$\mathrm{Pd}_{62} \mathrm{Au}_{139}$ & 56 & 0.71 & 6 & 0.11 \\
$\mathrm{Pd}_{67} \mathrm{Au}_{134}$ & 60 & 0.76 & 7 & 0.125 \\
$\mathrm{Pd}_{73} \mathrm{Au}_{128}$ & 63 & 0.80 & 10 & 0.18 \\
$\mathrm{Pd}_{79} \mathrm{Au}_{122}$ & 63 & 0.80 & 16 & 0.29 \\
$\mathrm{Pd}_{101} \mathrm{Au}_{100}$ & 76 & 0.96 & $24^{a}$ & 0.41 \\
\hline${ }^{a}$ Including one atom on (001) terrace. & & &
\end{tabular}

At low Pd:Au ratios there is no Pd at the surface (Table 2, Figure 1), and the structure of NP represents a bimetallic PdAu core surrounded by the one atomic layer thick purely $\mathrm{Au}$ shell. However, with the increase of Pd fraction, at $\rho_{\text {core }}^{P d}$ about 0.6, Au-isolated Pd atoms (Pd1 monomers) appear on the surface, first at $\mathrm{Pd}_{51} \mathrm{Au}_{150}$ composition (Figure 2a). Further increase of $\mathrm{Pd}$ fraction leads to the more pronounced presence of $\mathrm{Pd}$ on the surface as shown in Figure 2 for the compositions $\mathrm{Pd}_{67} \mathrm{Au}_{134}, \mathrm{Pd}_{79} \mathrm{Au}_{122}$, and $\mathrm{Pd}_{101} \mathrm{Au}_{100}$. At all considered compositions $\mathrm{Pd}$ is mostly distributed on the surface as Pd1 monomers. Pd2 dimers, when also present, are in much lower concentration. The surface location of Pd ensembles (monomers and dimers) is limited to (111) terraces. Only in the case of $\operatorname{Pd}_{101} \mathrm{Au}_{100}$, where the (111) terraces are almost saturated by Pd monomers (the saturation limit on $\mathrm{NP}_{201}$ is three Pd monomers per (111) facet that corresponds to $\theta_{\text {terrace }}^{P d}=0.43$; further increase of $\theta_{\text {terrace }}^{\text {Pd }}$ should involve ensembles of two and more atoms), one Pd monomer appeared also on (001) facet. In addition, $\mathrm{Pd}_{101} \mathrm{Au}_{100}$ exhibits homotops, $0.3-0.4 \mathrm{eV}$ above the lowest state, with single occupations of edge and corner sites by Pd. At none of other considered compositions was Pd found to be located in the lower-coordinated edge and corner sites, in line with the known higher stability of $\mathrm{Au}$ in low-coordinated positions of PdAu NPs [23] reflected by higher magnitudes of $\varepsilon_{C O R N E R}^{A u}$ and $\varepsilon_{E D G E}^{A u}$ descriptors than that of $\varepsilon_{T E R R A C E}^{A u}$ (Table 1). 


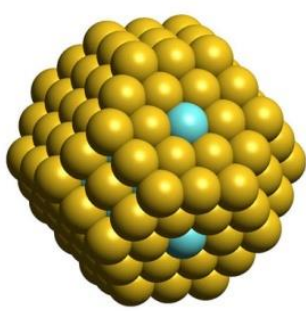

(a)

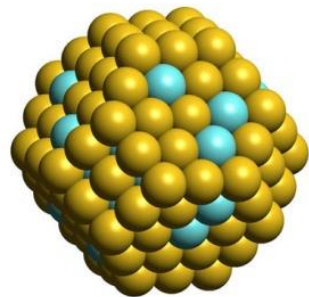

(c)

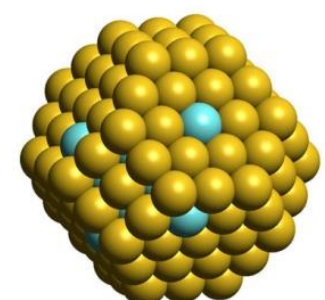

(b)

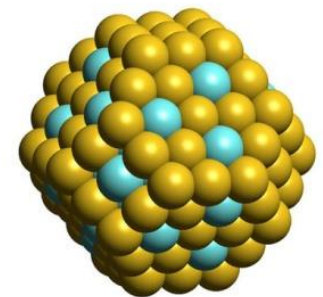

(d)

Figure 2. Views of the lowest-energy $\mathrm{NP}_{201}$ homotops with different elemental compositions: (a) $\mathrm{Pd}_{51} \mathrm{Au}_{150}$; (b) $\mathrm{Pd}_{67} \mathrm{Au}_{134}$; (c) $\mathrm{Pd}_{79} \mathrm{Au}_{122}$; (d) $\mathrm{Pd}_{101} \mathrm{Au}_{100}$. Pd atoms-light blue, $\mathrm{Au}$ atomsyellow. Concentration of $\mathrm{Pd}$ on the surface grows with increasing $\mathrm{Pd} / \mathrm{Au}$ ratio.

Remarkably, the dependence of $\theta_{\text {terrace }}^{P d}$ on $\rho_{\text {core }}^{P d}$ shown in Figure 1 is essentially nonlinear exhibiting two sharp increases, at $\rho_{\text {core }}^{P d}$ ca. 0.6 and 0.8 , and a rather flat plateau in between. Note, that a similar behavior was observed for PdAu (111) slabs using the Pd-Au EAM potential of Marchal et al. [19] in hybrid molecular-dynamics and MC simulations of Pd surface concentration as a function of Pd concentration inside a PdAu slab [45]. To rationalize the behavior shown in Figure 1 one has to consider the structural changes occurring inside the NP at growing $\rho_{\text {core }}^{P d}$.

\subsection{Ordered $\mathrm{PdAu} u_{3}$ Structures Surrounded by Au Outer Shell}

At low concentration Pd atoms tend to reside in inner part of the core of the model NP avoiding the direct contact to each other to maximize the number of energetically favorable $\mathrm{Pd}-\mathrm{Au}$ contacts (the energy of two Pd-Au bonds is slightly larger than the energy of one $\mathrm{Pd}-\mathrm{Pd}$ and one Au-Au bonds, as follows from comparison of homotops differing by a small number of bonds of different types). Thus, every Pd atom is coordinated by $12 \mathrm{Au}$ nearest neighbors in all compositions up to $\mathrm{Pd}_{22} \mathrm{Au}_{179}$, which represents the limiting case with the maximal number of Pd monomers in the core of $\mathrm{NP}_{201}$. Remarkably, low-energy homotops of $\mathrm{Pd}_{20} \mathrm{Au}_{181}$ and $\mathrm{Pd}_{22} \mathrm{Au}_{179}$ compositions exhibit ordered structures identical to the structures of $\mathrm{PdAu}_{3}$ bulk ordered phases $\mathrm{L}_{2}$ and $\mathrm{D0}_{22}$, respectively [46,47]. Figure 3 displays the frameworks of both NPs along with the corresponding bulk structures. The $\mathrm{L1}_{2}$ ordering was experimentally detected for ca. $5 \mathrm{~nm}$ large PdAu NPs [46]. According to DFT calculations of bulk alloys, both $\mathrm{L}_{2}$ and $\mathrm{D}_{22}$ structures exhibit rather high stability as manifested by the formation enthalpies $-97 \mathrm{meV} /$ atom and $-101 \mathrm{meV} /$ atom, respectively [47]. The realization of either $\mathrm{L1}_{2}$ or $\mathrm{DO}_{22}$ structures of such quite small particles as $\mathrm{NP}_{201}$ appears to be determined by $\mathrm{Pd}: \mathrm{Au}$ ratio with atomic accuracy. 


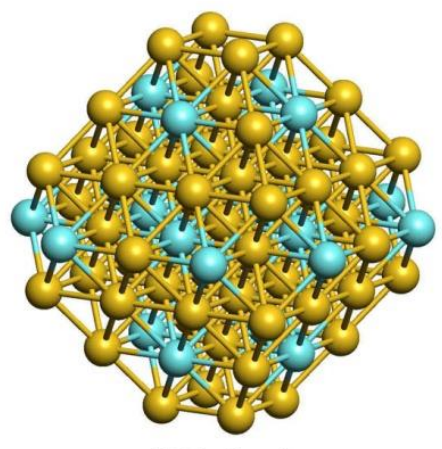

$\left[\mathrm{Pd}_{20} \mathrm{Au}_{59}\right.$

(a)

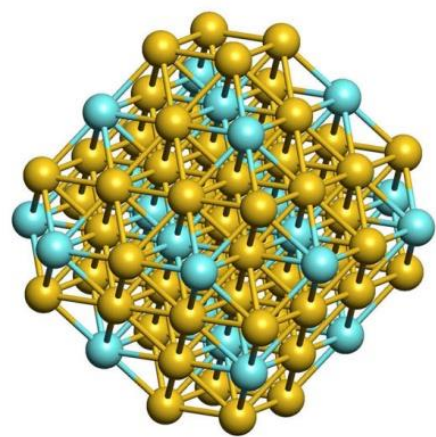

$\left[\mathrm{Pd}_{22} \mathrm{Au}_{57}\right.$

(b)

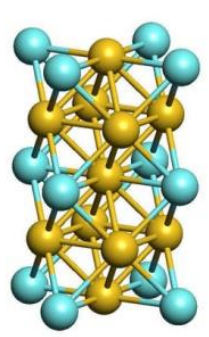

$\mathrm{L}_{2} \mathrm{PdAu}_{3}$

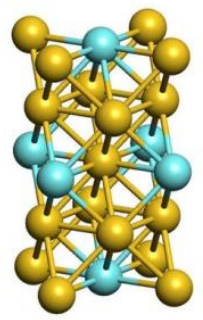

$\mathrm{DO}_{22} \mathrm{PdAu}_{3}$

Figure 3. (a) The ordered core $\left[\mathrm{Pd}_{20} \mathrm{Au}_{59}\right]$ (left) of $\mathrm{Pd}_{20} \mathrm{Au}_{181} \mathrm{NP}$ with atomic order identical to the bulk phase $\mathrm{L}_{2} \mathrm{PdAu}_{3}$ (right). (b) The core $\left[\mathrm{Pd}_{22} \mathrm{Au}_{57}\right]$ of $\mathrm{Pd}_{22} \mathrm{Au}_{179} \mathrm{NP}$ with atomic order identical to $\mathrm{D}_{22} \mathrm{PdAu}_{3}$. All Pd atoms of the both structures are distributed inside the particles without contacting each other, i.e., there are no Pd-Pd bonds. Thus, the core structure represents $\mathrm{PdAu}$ alloy of approximately 1:3 ratio surrounded by a purely Au shell. The outer shell of $\mathrm{Pd}_{20} \mathrm{Au}_{181}$ and $\mathrm{Pd}_{22} \mathrm{Au}_{179}$ consisting of $122 \mathrm{Au}$ atoms is not shown.

When the number of Pd atoms exceeds 22 (28\% of total core atoms), Pd-Pd bonds start to be formed inside the core. For instance, there are two Pd-Pd bonds in $\mathrm{Pd}_{23} \mathrm{Au}_{178}$ : a linear $\mathrm{Pd} 3$ trimer is formed via substitution of an $\mathrm{Au}$ atom coordinated by two $\mathrm{Pd}$ atoms in $\mathrm{Pd}_{22} \mathrm{Au}_{179}$ structure. The lowest-energy homotop $\mathrm{Pd}_{24} \mathrm{Au}_{177}$ already contains four Pd-Pd bonds: Two Pd2 dimers and one linear Pd3 trimer. Still, the main motif of the bulk-like ordered structure is preserved. Location of Pd atoms in the surface shell is unfavorable and the increase of Pd concentration/density in the core leads to increase of the total number of Pd-Au bonds, which stabilize the bimetallic system with respect to the monometallic counterparts.

\subsection{Enrichment of Subsurface Shell by Pd Prior to Formation of Pd Surface Monomers}

When the Pd fraction is increased up to about $60 \%$ of the NP core, the most stable homotops start to exhibit Pd1 monomers on the surface, see a sharp transition to non-zero $\theta_{\text {terrace }}^{P d}$ in Figure 1. For instance, there are three and six Pd atoms on (111) facets (single Pd per facet) in the lowest-energy homotops of $\mathrm{Pd}_{51} \mathrm{Au}_{150}$ and $\mathrm{Pd}_{56} \mathrm{Au}_{145}$ compositions, respectively. The concentration of $\mathrm{Pd}$ in the core is 60 and $63 \%$, respectively (Table 2, Figure 1). Here, the location of Pd atoms in the outer shell positions with the highest coordination number (9 for (111) facets) is in line with previous results $[19,21]$ and directly follows from the topological energy expression. Structural analysis of the low-lying homotops $\mathrm{Pd}_{51} \mathrm{Au}_{150}$ and $\mathrm{Pd}_{56} \mathrm{Au}_{145}$ reveals that all of them are based on the ordered core $\left[\mathrm{Pd}_{48} \mathrm{Au}_{31}\right]$. The formula of the core is in brackets as a part of $\mathrm{NP}_{201}$ to distinguish it from an individual $\mathrm{NP}_{79}$ of the same nuclearity, which is often used in theoretical modeling. 
Inspection of the energetics of $\mathrm{Pd}_{48} \mathrm{Au}_{153}$ homotop shows that the structure with the ordered core $\left[\mathrm{Pd}_{48} \mathrm{Au}_{31}\right]$ (see Figure 4) surrounded by the $\mathrm{Au}_{122}$ shell is stable to any $\mathrm{Pd}-\mathrm{Au}$ permutation between the core and the outer shell. On the other hand, an additional $\mathrm{Pd}$ atom of the next composition, $\mathrm{Pd}_{49} \mathrm{Au}_{152}$, is stable on the surface. In terms of topological energy expression, Equation (1), the stabilization energy of a single $\mathrm{Pd}$ atom on the (111) facet of $\mathrm{Pd}_{49} \mathrm{Au}_{152}$ is

$$
\Delta E_{C O R E \leftrightarrow T E R R A C E}=-\varepsilon_{T E R R A C E}^{A u}+9 \varepsilon_{B O N D}^{A u-P d}
$$
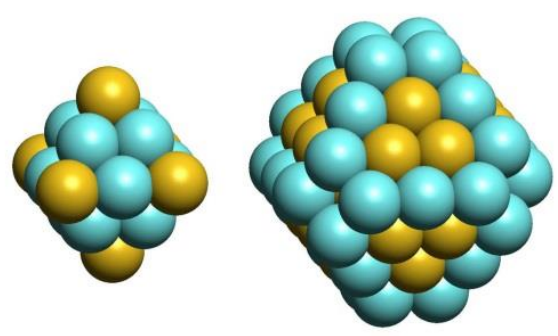

Figure 4. The ordered core structure $\left[\mathrm{Pd}_{48} \mathrm{Au}_{31}\right]$ of $\mathrm{Pd}_{51} \mathrm{Au}_{150}$ and $\mathrm{Pd}_{56} \mathrm{Au}_{145}$ lowest-energy homotops. The first shell of 18 atoms (left) is built around the central Au atom to form a regular octahedron. The second shell (right) comprises 60 atoms. Completion of the outer shell (not shown) by $122 \mathrm{Au}$ atoms leads to a stable $\mathrm{Pd}_{48} \mathrm{Au}_{153}$ homotop without surface $\mathrm{Pd}$.

Applying the descriptors optimized for $\mathrm{Pd}_{56} \mathrm{Au}_{145}$ composition one obtains exothermic effect $\triangle E_{C O R E \leftrightarrow T E R R A C E}=-0.04 \mathrm{eV}$, which substantiates favorable location of additional Pd atom in the outer shell. The critical value to obtain a stable Pd atom in the surface shell for this configuration is $\varepsilon_{T E R R A C E}^{A u} / \varepsilon_{B O N D}^{A u-P d}<9$, that is the case for the topological descriptors obtained for compositions $\mathrm{Pd}_{56} \mathrm{Au}_{145}$ and $\mathrm{Pd}_{67} \mathrm{Au}_{134}$. However, the descriptors for compositions $\mathrm{Pd}_{79} \mathrm{Au}_{122}$ and $\mathrm{Pd}_{101} \mathrm{Au}_{100}$ with higher $\mathrm{Pd}$ content exhibit $\varepsilon_{T E R R A C E}^{A u} / \varepsilon_{B O N D}^{A u-P d}>9$. Therefore, they are not suitable for accurate enough representation of compositions with the lower Pd content.

Thus, the ordered core structure $\left[\mathrm{Pd}_{48} \mathrm{Au}_{31}\right]$ is rather stable and at further increase of $\mathrm{Pd}$ fraction in the $\mathrm{NP}_{201}$ the excessive Pd atoms $(>48)$ go to the surface forming "single atoms" on (111) facets. This structure $\left[\mathrm{Pd}_{48} \mathrm{Au}_{31}\right]$ is also remarkable in the sense that this non-bulk-like ordering originates from the structural peculiarities of the NP. Pd atoms in the subsurface shell occupy edge and corner sites of the truncated octahedron $\left[\mathrm{Pd}_{48} \mathrm{Au}_{31}\right]$, while $\mathrm{Au}$ atoms are located on (111) facets of the latter. Thus, the preference for $\mathrm{Pd} / \mathrm{Au}$ ordering in the subsurface shell exhibits a reverse pattern to the outer shell ordering, where $\mathrm{Pd}$ first emerges on the facets leaving corner and edge sites to be more favorably occupied by $\mathrm{Au}$ atoms. Evidently, such distribution of $\mathrm{Pd}$ and $\mathrm{Au}$ atoms alternating with each other in the neighboring shells maximizes the number of Pd-Au bonds, thus increasing the stability.

\subsection{Ordered PdAu Bulk-Like Structure}

Further increase of Pd fraction leads to a considerable increase of $\rho_{\text {core }}^{P d}$ from 0.63 in $\mathrm{Pd}_{56} \mathrm{Au}_{145}$ to 0.71 and 0.76 in $\mathrm{Pd}_{62} \mathrm{Au}_{139}$ and $\mathrm{Pd}_{67} \mathrm{Au}_{134}$, respectively (Table 2). However, the number of six surface $\mathrm{Pd}$ atoms in the lowest-energy homotop $\mathrm{Pd}_{62} \mathrm{Au}_{139}$ remains the same as in $\mathrm{Pd}_{56} \mathrm{Au}_{145}$ and the number only slightly increases to seven in $\operatorname{Pd}_{67} \mathrm{Au}_{134}$. This results in a plateau in Figure 2 corresponding to $\theta_{\text {terrace }}^{\text {Pd }} \approx 0.11$. A detailed analysis shows that the composition $\mathrm{Pd}_{62} \mathrm{Au}_{139}$ exhibits several low-lying homotops with different numbers of Pd atoms in the outer shell and quite different patterns of the Pd-Au ordering in the inner core. Structures of three selected homotops are shown in Figure 5: $\left[\mathrm{Pd}_{60} \mathrm{Au}_{19}\right] \mathrm{Pd}_{2} \mathrm{Au}_{120}(5 \mathrm{a}),\left[\mathrm{Pd}_{56} \mathrm{Au}_{23}\right] \mathrm{Pd}_{6} \mathrm{Au}_{116}(5 \mathrm{~b})$, and $\left[\mathrm{Pd}_{54} \mathrm{Au}_{25}\right] \mathrm{Pd}_{8} \mathrm{Au}_{114}$ (5c) with outer shells containing two (5a), six (5b), and eight (5c) Pd1 monomers. The TOP precision $\delta$ is limited for the studied 201-atomic PdAu NPs to $0.2-0.3 \mathrm{eV}$ (Table 1) with the chosen 
structure of the topological expression (Equation (1)). This justifies the overestimated TOP stability of structures with low $\theta_{\text {terrace }}^{\text {Pd }}$ yielding the lowest energy for 5 a with the ordered core $\left[\mathrm{Pd}_{60} \mathrm{Au}_{19}\right]$ (Figure 5), while DFT gives a clear preference to higher $\theta_{\text {terrace, }}^{P d}$ as $5 \mathrm{~b}$ and $5 c$, putting these homotops, respectively, 0.16 and $0.12 \mathrm{eV}$ lower than $5 \mathrm{a}$. At the TOP level, the energy difference between $5 a, b$ is

$$
\Delta E_{5 a \rightarrow 5 b}=-4 \varepsilon_{T E R R A C E}^{A u}+30 \varepsilon_{B O N D}^{A u-P d}
$$
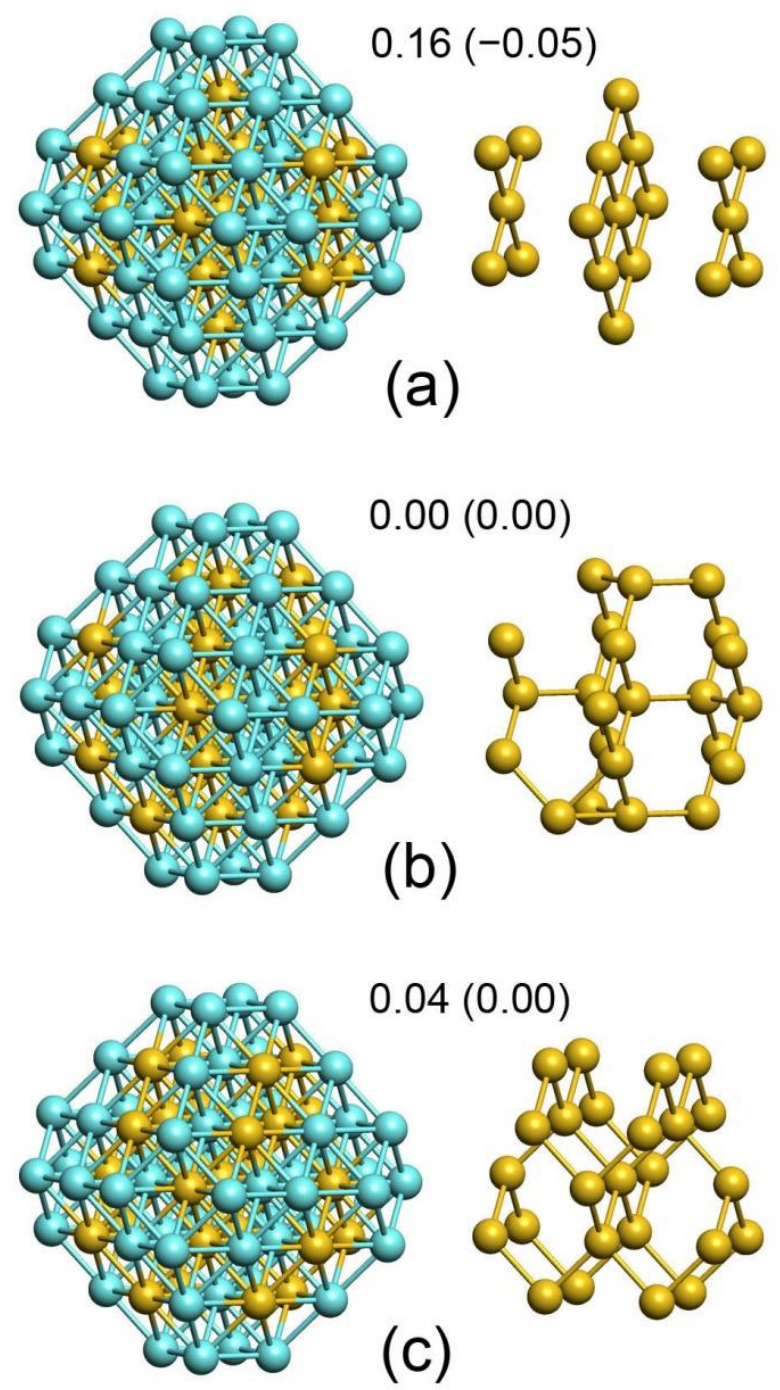

Figure 5. Core structures of $\mathrm{Pd}_{62} \mathrm{Au}_{139}$ homotops with different number of surface $\mathrm{Pd}$ atoms: (a) $\left[\mathrm{Pd}_{60} \mathrm{Au}_{19}\right],(\mathbf{b})\left[\mathrm{Pd}_{56} \mathrm{Au}_{23}\right]$ and (c) $\left[\mathrm{Pd}_{54} \mathrm{Au}_{25}\right]$. The left column presents the complete core structures while the right column shows only $\mathrm{Au}$ atoms of the core for a clear view of the atomic ordering. The outer shells of the homotops (not shown) contain two (a), six (b), and eight Pd1 monomers (c). Relative energies of the homotops (in eV) obtained by DFT and TOP (in parenthesis) approaches are also presented.

Thus, the homotop 5a has the lowest $E_{\mathrm{TOP}}$ with $\varepsilon_{T E R R A C E}^{A u} / \varepsilon_{B O N D}^{A u-P d}>7.5$ that is the case already for $\mathrm{Pd}_{67} \mathrm{Au}_{134}$ as well as for higher Pd:Au ratios (Table 1). Nevertheless, the DFT data favor the states with higher $\theta_{\text {terrace }}^{P d}$, such as $5 \mathrm{~b}, \mathrm{c}$ with disordered core structures (Figure 5). We rely on DFT energies to make the final conclusions on $\mathrm{Pd} / \mathrm{Au}$ distribution in $\mathrm{NP}_{201}$. However, the observations on TOP descriptors made in this work are important for better understanding the abilities and limitations of the TOP approach, especially 
when it is applied to large NPs, exceedingly demanding DFT calculations of which still remain impractical.

The homotops $5 \mathrm{~b}, \mathrm{c}$ are iso-energetic at $\varepsilon_{T E R R A C E}^{A u} / \varepsilon_{B O N D}^{A u-P d}=8$, since the energy difference between them is $\Delta E_{5 b \rightarrow 5 c}=-2 \varepsilon_{T E R R A C E}^{A u}+16 \varepsilon_{B O N D}^{A u-P d}$. In the absence of the explicitly calculated TOP descriptors for the composition $\mathrm{Pd}_{62} \mathrm{Au}_{139}$, one can estimate the value $\varepsilon_{T E R R A C E}^{A u} / \varepsilon_{B O N D}^{A u-P d} \approx 7.9$ by the interpolation of the descriptors listed in Table 1 for other compositions (see Supplementary Materials, Figure S1, Table S1 for more detail). On the other hand, $5 \mathrm{a}$ is the lowest-energy homotop according to DFT calculations with the energy just 0.04 lower than that of $5 \mathrm{~b}$ homotop. This energy difference is too small to be conclusive. Nevertheless, it illustrates how sensitive is the value of $\theta_{\text {terrace }}^{P d}$ to the values of TOP descriptors. A number of found homotops with significantly higher Pd surface fractions of 11-18 atoms have $0.2-1.0 \mathrm{eV}$ higher energies than the lowest-lying homotops both at the DFT and TOP levels (see Supplementary Materials, Table S2). Applying the Boltzmann factor to define the populations of the lowest five homotops of $\mathrm{Pd}_{62} \mathrm{Au}_{139}$ (including $5 \mathrm{~b}, \mathrm{c}$ ) at $300 \mathrm{~K}$ one gets the average $\theta_{\text {terrace }}^{\text {Pd }}=0.126$, which is only slightly higher than 0.107 corresponding to $5 \mathrm{~b}$ homotop at $0 \mathrm{~K}$.

The ordered core structure $\left[\mathrm{Pd}_{60} \mathrm{Au}_{19}\right]$ of $5 \mathrm{a}$ is very peculiar because of its high stability along with high $\mathrm{Pd}$ density. If surrounded by purely gold shell, $\left[\mathrm{Pd}_{60} \mathrm{Au}_{19}\right] \mathrm{Au}_{122}$, this structure is stable to single permutations of $\mathrm{Pd}$ and $\mathrm{Au}$ atoms between the core and the skin. The arrangement of $\mathrm{Au}$ atoms in $\left[\mathrm{Pd}_{60} \mathrm{Au}_{19}\right]$ (Figure 5a) is identical to $\mathrm{L1}_{0} \mathrm{PdAu}$ bulk structure with $\mathrm{Pd}$ and Au layers alternating in [001] direction. The $\mathrm{L} 1_{0}$ was observed experimentally for PdAu NPs [46]. According to DFT bulk calculations, L1 $1_{0}$ phase is highly stable with the formation enthalpy $-104 \mathrm{meV} /$ atom; only PdAu bulk phase $\mathrm{Nr} 40$ is slightly more stable with the formation enthalpy $-118 \mathrm{meV} /$ atom [47]. It is a remarkable feature of the nanostructure $\left[\mathrm{Pd}_{60} \mathrm{Au}_{19}\right]$ that most of $\mathrm{Au}$ core atoms are located in the inner part of the core, which has the shape of a regular 19-atomic octahedron, with only four $\mathrm{Au}$ atoms in the subsurface shell. High Pd content in the subsurface shell compared to the inner core was reported on the basis of DFT-parameterized EAM modeling [19]. [ $\left.\mathrm{Pd}_{60} \mathrm{Au}_{19}\right]$ core represents the situation of the subsurface shell almost completely, by $93 \%$, composed of Pd.

Although in $\operatorname{Pd}_{62} \mathrm{Au}_{139}$ composition disordered cores with lower $\rho_{\text {core }}^{P d}(5 \mathrm{~b}, \mathrm{c})$ are preferred at the DFT level, the lowest-energy two $\mathrm{Pd}_{67} \mathrm{Au}_{134}$ homotops (with degenerate DFT energies) are based on the ordered core structure $\left[\mathrm{Pd}_{60} \mathrm{Au}_{19}\right]$ (5a) with its high $\rho_{\text {core }}^{P d}, 0.76$. Note, that another low-lying homotop (not further specified in the article) featuring only $0.01 \mathrm{eV}$ higher energy exhibits the core $\left[\mathrm{Pd}_{61} \mathrm{Au}_{18}\right]$ with even higher $\rho_{\text {core }}^{P d}$ and contains elements of the bulk PdAu phase Nr. 40, the most stable for PdAu alloys according to DFT calculations [47]. Thus, $\operatorname{Pd}_{67} \mathrm{Au}_{134}$ composition is at the end of the flat part of the curve in Figure 1. Here, a rather low $\theta_{\text {terrace }}^{\text {Pd }}=0.125$ is accompanied by the subsurface shell composed of Pd by more than $90 \%$ and the atomic ordering in the inner core similar to that of PdAu bulk (with 1:1 ratio).

Further increase of $\mathrm{Pd}$ fraction in $\mathrm{NP}_{201}$ leads to compositions $\mathrm{Pd}_{73} \mathrm{Au}_{128}$ and $\mathrm{Pd}_{79} \mathrm{Au}_{122}$ (Table 1), both of which exhibit in their lowest homotops the ordered core $\left[\mathrm{Pd}_{63} \mathrm{Au}_{16}\right]$ (see Figure 6) with $\rho_{\text {core }}^{P d}=0.8$ being only slightly higher than that of $\mathrm{Pd}_{67} \mathrm{Au}_{134}$ composition considered above. Similar to $\mathrm{Pd}_{48} \mathrm{Au}_{153}$ and $\mathrm{Pd}_{51} \mathrm{Au}_{150}$, where the transition to non-zero $\theta_{\text {terrace }}^{P d}$ occurs, formation of a stable ordered core leads here to fast increase of $\theta_{\text {terrace }}^{\text {Pd }}$ (Figure 1) from 0.18 in $\mathrm{Pd}_{73} \mathrm{Au}_{128}$ to 0.29 in $\mathrm{Pd}_{79} \mathrm{Au}_{122}$ (Table 2). As at lower Pd content, the surface $\mathrm{Pd}$ fraction of $\mathrm{Pd}_{79} \mathrm{Au}_{122}$ is represented by $\mathrm{Pd} 1$ monomers surrounded by $\mathrm{Au}$ atoms on (111) terraces. Noteworthily, $\mathrm{Pd}_{79} \mathrm{Au}_{122}$ homotop with pure $\mathrm{Pd}$-core/Au-shell structure is ca. $0.8 \mathrm{eV}$ higher in energy (both at DFT and TOP levels) than the lowest-lying homotop. 


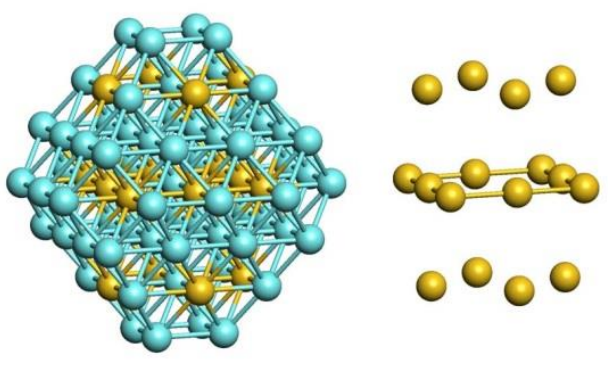

Figure 6. The ordered core structure $\left[\mathrm{Pd}_{63} \mathrm{Au}_{16}\right]$ (left) and only Au atoms there (right) of the lowestenergy homotops $\mathrm{Pd}_{73} \mathrm{Au}_{128}$ and $\mathrm{Pd}_{79} \mathrm{Au}_{122}$.

Saturation of the NP core by $\mathrm{Pd}$ is reached in $\mathrm{Pd}_{101} \mathrm{Au}_{100}$ composition (Figure 1, Table 2). This configuration marks the following limits for occupation of core and terraces by Pd: (i) The core of NP in the lowest-energy homotops is completely $(100 \%)$ or almost completely (96-98\%) formed of Pd atoms; (ii) occupation of (111) terraces by Pd1 monomers in the lowest-energy homotops reaches $40 \%$ (22-24 Pd atoms). Three $\mathrm{Pd}$ atoms per terrace is the saturation limit for monomers on (111) terraces of $\mathrm{NP}_{201}$ (Figure 2d). Formation of $\operatorname{Pd}_{n}(n>1)$ moieties on (111) facets and occupation of (001) facets by Pd start at higher Pd surface concentrations.

To summarize, the following picture emerges from the results obtained for $\mathrm{NP}_{201}$ : (i) At low content Pd is completely located inside the core; (ii) when Pd concentration in the core reaches ca. $60 \%$, Pd appears also on the surface in the form of single Pd1 centers (monomers) surrounded by $\mathrm{Au}$ atoms; (iii) at further increase of $\mathrm{Pd}: \mathrm{Au}$ ratio the core becomes completely formed of $\mathrm{Pd}$, and simultaneously the concentration of $\mathrm{Pd} 1$ species on (111) terraces reaches the saturation limit of ca. $40 \%$.

\subsection{Generalization to Larger Particles: $N P_{586}$ and $N P_{1289}$}

PdAu NPs of model catalysts studied experimentally are 4-12 nm large with the mean size about $7 \mathrm{~nm}[13,14]$. The theoretical model $\mathrm{NP}_{201}$ has a diameter $D=1.7 \mathrm{~nm}$ (the diameter of a sphere built on the vertex atoms of the truncated octahedron is meant here). To approach the size range of particles dealt with experimentally, the TOP method was applied to $\mathrm{PdAu}$ model particles $\mathrm{NP}_{586}$ and $\mathrm{NP}_{1289}$ with the same shape as $\mathrm{NP}_{201}$ and $D=2.6$ and $3.5 \mathrm{~nm}$, respectively. These particles are fully isomorphic with $\mathrm{NP}_{201}$ discussed in detail above. Their main differences from the smaller model $\mathrm{NP}_{201}$ are smaller surface/core ratios, which decrease with increasing particle size. The number of surface atoms in $\mathrm{NP}_{201}$ is 1.54 times larger than the number of core atoms (122 atoms on the surface and 79 atoms in the core). The notably smaller surface/core ratios, 0.87 for $\mathrm{NP}_{586}$ and 0.60 for $\mathrm{NP}_{1289}$, reflect that there are more atoms in the core than on the surface of these larger particles.

A correspondence between the concentrations of metal components in the core and in the surface shell of PdAu NP 201 (Figure 1) has been established in Section 3.2. To apply this correspondence to NPs of arbitrary size one has to take into account that at the same Pd:Au ratio the distribution of two metal components between core and surface may be size-dependent due to a varying surface/core ratio. For instance, in $\mathrm{NP}_{201}$ with 1:1 Pd:Au ratio (composition $\mathrm{Pd}_{101} \mathrm{Au}_{100}$ ), the number of $\mathrm{Pd}$ atoms exceeds the total number of the core atoms resulting in the core almost saturated by $\mathrm{Pd}\left(\rho_{\text {core }}^{P d}=0.98\right)$. However, in $\mathrm{NP}_{1289}$ with the same 1:1 Pd:Au ratio (composition $\mathrm{Pd}_{645} \mathrm{Au}_{644}$ ), the number of $\mathrm{Pd}$ atoms is about $20 \%$ smaller than the number of the core atoms, 807 . Therefore, according to Figure 1 considerable $\mathrm{Au}$ fraction in the core is expected in contrast to $\operatorname{Pd}_{101} \mathrm{Au}_{100}$. Furthermore, a notably lower $\theta_{\text {terrace }}^{P d}$ is expected for $\operatorname{Pd}_{645} \mathrm{Au}_{644}$ compared to $\operatorname{Pd}_{101} \mathrm{Au}_{100}$. Since $\rho_{\text {core }}^{P d} \sim 0.6$ is shown to be the threshold value, above which Pd atoms become stable on the surface of $\mathrm{NP}_{201}$; we plot this value in Figure 7 for Wulff-type particles of increasing size (circles in 
Figure 7) ranging from $\mathrm{NP}_{201}$ to $\mathrm{NP}_{12934}(D=7.8 \mathrm{~nm})$. Below this line the whole Pd fraction is expected to reside in the core of NPs confined by purely Au shell $\left(\theta_{\text {terrace }}^{P d}=0\right)$.

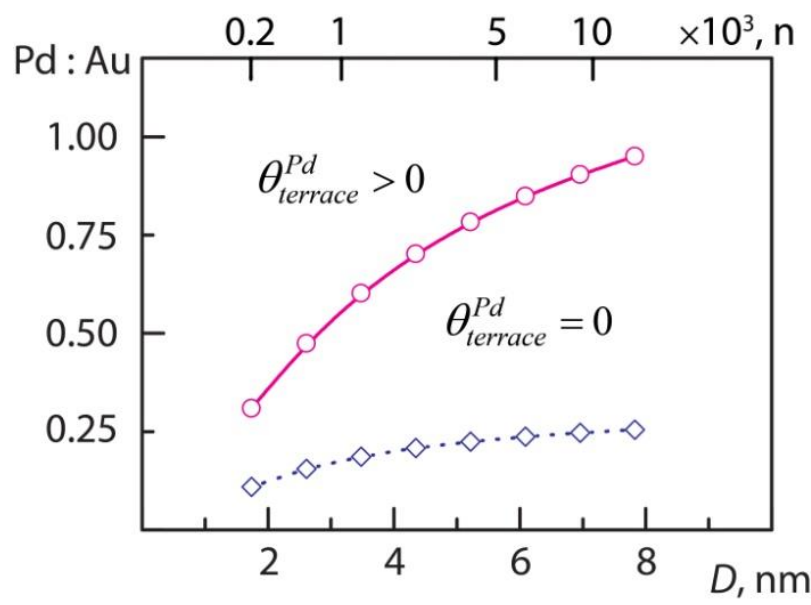

Figure 7. Conditions for existence of Pd surface species on the surface of PdAu truncated-octahedral NPs with a given Pd:Au ratio and diameter $D, n$ m (the upper scale shows also the NP nuclearity, $n$ ). The solid line (circles) corresponds to Pd concentration $\rho_{\text {core }}^{P d}=0.6$ in the core covered with Au shell $\left(\theta_{\text {terrace }}^{P d}=0\right)$. With the increase of $\rho_{\text {core }}^{P d}$ above this line, Pd1 monomers and ensembles become stable on the surface of NPs $\left(\theta_{\text {terrace }}^{P d}>0\right)$; below is the region with Pd fraction residing inside the core surrounded by the purely Au shell. The dashed line (diamonds) corresponds to $\rho_{\text {core }}^{P d}=0.25$, where a bulk-like $\mathrm{PdAu}_{3}$ ordering is expected. Below this line, $0<\rho_{\text {core }}^{P d}<0.25$, Pd fraction is distributed in the form of single Pd atoms in the core of NPs.

From the data in Figure 7 one can expect appearance of Pd1 monomers on the surface of $\mathrm{NP}_{586}$ for ca. 1:2 Pd:Au ratio. Indeed, applying the TOP approach to $\mathrm{Pd}_{199} \mathrm{Au}_{387}$ and $\mathrm{Pd}_{219} \mathrm{Au}_{367}$ compositions of $\mathrm{NP}_{586}$ resulted in the lowest-energy homotops with $\theta_{\text {terrace }}^{\text {Pd }}$ of 0.02 (6 Pd1 monomers) and 0.08 (12 Pd1), respectively. The corresponding Pd fractions in the core, $\rho_{\text {core }}^{P d}$, are 0.62 and 0.66 . The topological energy descriptors of $\mathrm{Pd}_{56} \mathrm{Au}_{145}$ composition were used here and the obtained $\rho_{\text {core }}^{P d}$ and $\theta_{\text {terrace }}^{P d}$ values are quite consistent with the trend shown in Figure 1.

Furthermore, employing the same approach to $\mathrm{Pd}_{511} \mathrm{Au}_{778}$ composition of $\mathrm{NP}_{1289}$ (Figure 8 ) one obtains $\theta_{\text {terrace }}^{P d}=0.11$ and $\rho_{\text {core }}^{P d}=0.60$, in agreement with the estimations derived from Figures 1 and 7 . The $\mathrm{Pd}_{511} \mathrm{Au}_{778}$ homotop displayed in Figure 8 exhibits the atomic ordering similar to that of $\mathrm{NP}_{201}$ at similar $\rho_{\text {core }}^{P d}$ and $\theta_{\text {terrace }}^{P d}$ values: Pd species are scattered in the outer shell as monomers (27 Pd1 in total) and dimers ( $3 \mathrm{Pd} 2)$, while the subsurface shell is enriched by Pd. Noteworthy, edges of the subsurface shell show preference for hosting Pd atoms, while Au atoms are located on terraces of this shell. The average number of $\mathrm{Pd}-\mathrm{Au}$ bonds per $\mathrm{Pd}$ atom in $\mathrm{Pd}_{511} \mathrm{Au}_{778}$ is 7.4, slightly lower than the value 8.3 found for $\operatorname{Pd}_{56} \mathrm{Au}_{145}$.

Figure 7 also shows the region where the bulk-like $\mathrm{PdAu}_{3}$ ordering is expected: the dashed line corresponds to $\rho_{\text {core }}^{P d}=0.25$ (diamonds in Figure 7 correspond to the nuclearities of Wulff-type NPs). Below this line Pd fraction is distributed in the form of Pd monomers in the core of NPs. It is clearly seen in Figure 7 that for 5-8 nm large particles the fraction of surface atoms (Au shell) is small compared to the core. Therefore, the total $\mathrm{Pd} / \mathrm{Au}$ ratio required for the $\mathrm{PdAu}_{3}$ phase $\mathrm{L1}_{2}$ to be formed in the core is only slightly lower than 0.25 . Indeed, $\mathrm{L1}_{2}$ phase was reported for NPs larger than $5 \mathrm{~nm}$ [46]. However, lower Pd/Au ratios appear to be optimal for the core ordering $\mathrm{PdAu}_{3}$ in smaller NPs, e.g., $\sim 0.15$ and $\sim 0.2$ for 2.5 and $4 \mathrm{~nm}$ large NPs, respectively. 

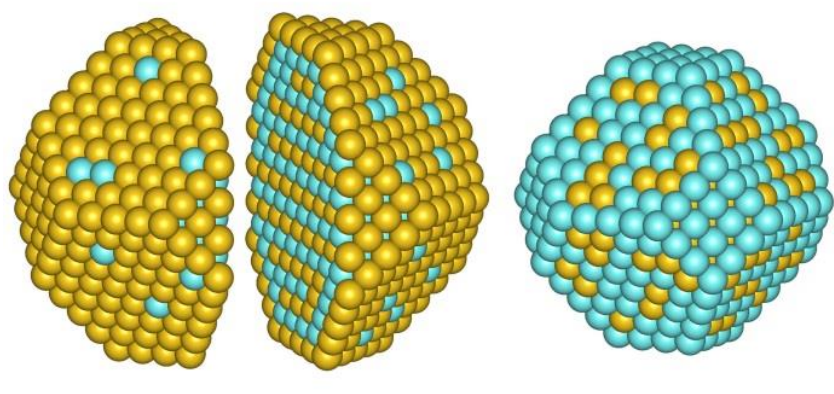

Figure 8. The structure of $\mathrm{Pd}_{511} \mathrm{Au}_{778}\left(\mathrm{NP}_{1289}\right)$ found after 10 million $\mathrm{MC}$ steps to minimize the topological energy, Equation (1), using the descriptors for the $\mathrm{NP}_{201}$ composition $\mathrm{Pd}_{56} \mathrm{Au}_{145}$ : the outer shell consisting of 482 atoms (left and center), cross section (center) and the subsurface shell (right).

The activity and selectivity of bimetallic catalysts are often discussed using the concept of the ensemble (geometric) and ligand (electronic) effects [13,48-51]. These effects originate from the formation of contiguous palladium domains, when diluting $\mathrm{Pd}$ with $\mathrm{Au}$, and charge transfer between Au and Pd or orbital re-hybridization of metal atoms involved in heteronuclear metal-metal bonds. Most studies have been focused on the ensemble effect. The catalytic performance of PdAu nanoalloys strongly correlates with the $\mathrm{Pd} / \mathrm{Au}$ ratio. The current work provides the relationship between the $\mathrm{Pd} / \mathrm{Au}$ ratio in core of bimetallic particles, particles size, and surface structure of the Pd sites. Such data could be used as a basis for synthesis of Pd single-site catalysts for application in a number of catalytic reactions.

\section{Conclusions}

Using DFT approach and DFT-parameterized topological energy expressions we studied the distribution of metal components in bimetallic PdAu nanoparticles. One of the main findings is that already at very low temperature single-atom Pd1 centers become stable in the outer surface shell of nanoparticles formed by Au atoms at the concentration of $\mathrm{Pd}$ in the particle core exceeding ca. $60 \%$. The present modeling approach can be extended to other nanoalloys in order to establish their compositions at which single-atom surface centers are stable. Such data will pave the way to approaching elusive aim of the knowledge-driven designing very selective catalysts exposing active metal sites of just one type.

The general mechanism of $\mathrm{Pd}$ and $\mathrm{Au}$ ordering in $\mathrm{PdAu}$ nanoparticles can be rationalized by interplay of two effects: (i) the miscibility of $\mathrm{Pd}$ and Au manifesting itself in maximizing the number of $\mathrm{Pd}-\mathrm{Au}$ bonds in the minimum-energy atomic orderings and (ii) the stabilization of purely $\mathrm{Au}$ atomic outer shell of the nanoparticles, when Pd concentration in their inner region is lower than the threshold value. Concentration of the surface Pd1 centers is a function of Pd concentration in the particle core.

Analysis of structural changes with the increase of $\mathrm{Pd}$ fraction shows various ordering types in the cores of model nanoparticles. At very low Pd concentrations the whole Pd fraction is distributed in the core as Pd1 monomers coordinated by $12 \mathrm{Au}$ atoms. When $\mathrm{Pd}$ concentration in the core is increased to ca. 0.25 , ordered bulk-like $\mathrm{PdAu}_{3}$ structures confined by the gold outer shell are formed. Interestingly, for small particles such as $\mathrm{NP}_{201}$ the emergence of either $\mathrm{L1}_{2}\left(\mathrm{Pd}_{20} \mathrm{Au}_{181}\right)$ or $\mathrm{D0}_{22}\left(\mathrm{Pd}_{22} \mathrm{Au}_{179}\right)$ orderings is determined by a tiny variation of the $\mathrm{Pd}: \mathrm{Au}$ ratio. Further increase of $\mathrm{Pd}$ fraction leads to more dense $\mathrm{Pd}$ distribution in the core with formation of Pd-Pd bonds. Non-bulk orderings in the core accompany formation of stable surface Pd1 monomers: The subsurface shell is enriched by $\mathrm{Pd}$ with the edges of this shell fully occupied by $\mathrm{Pd}$ atoms, while $\mathrm{Au}$ atoms are located in (111) terraces of the subsurface shell. Thus, the occupation order of terrace-edge positions in the subsurface shell of a PdAu nanoparticle is inversed for Pd and Au with respect to the outer shell. 
Supplementary Materials: The following data are available online at https:/ /www.mdpi.com/ 2079-4991/11/1/122/s1, Figure S1: Topological energy descriptors as function of Pd:Au ratio in the compositions PdmAu201 $-\mathrm{m}(\mathrm{m}=56,79,101)$ of model NP201; Table S1: Topological energy descriptors for compositions PdmAu201 - $\mathrm{m}(\mathrm{m}=51,62,67,73)$ of NP201; Table S2: Energetic and topological characteristics of low-lying homotops of PdmAu201-m compositions with $\mathrm{m}=51$, 56, 62, 67, 73, 79; Table S3: Energetic and topological characteristics of low-lying homotops of Pd101Au100 composition.

Author Contributions: Conceptualization, M.M., I.V.Y., A.V.B., and K.M.N.; methodology, M.M., I.V.Y., and K.M.N.; software, M.M. and K.M.N.; investigation, M.M. and I.V.Y.; validation, I.V.Y. and A.V.B.; formal analysis, M.M. and I.V.Y.; resources, M.M. and K.M.N.; data curation, M.M. and I.V.Y.; writing-original draft preparation, I.V.Y. and K.M.N.; writing-review and editing, M.M., I.V.Y., A.V.B., and K.M.N.; visualization, I.V.Y. and K.M.N.; supervision, I.V.Y. and K.M.N. All authors have read and agreed to the published version of the manuscript.

Funding: This work was supported by the Russian Science Foundation, grant no. 20-23-05002 for BIC SB RAS. K.M.N. gratefully acknowledges support by the Spanish grants PGC2018-093863-B-C22, MDM-2017-0767 and PRX17/00348 as well as by the grant 2017SGR13 of the Generalitat de Catalunya.

Institutional Review Board Statement: Not applicable.

Informed Consent Statement: Not applicable.

Data Availability Statement: The data presented in this study are available in Supplementary Materials.

Acknowledgments: I.V.Y. thanks Kirill V. Yudanov for extensive financial support. K.M.N. thanks the European Cooperation in Science and Technology program via the COST Action 18234. The authors are grateful to Red Española de Supercomputación and Novosibirsk Siberian Supercomputing Center for generously provided computational resources.

Conflicts of Interest: The authors declare no conflict of interest.

\section{References}

1. Ferrando, R.; Jellinek, J.; Johnston, R.L. Nanoalloys: From theory to applications of alloy clusters and nanoparticles. Chem. Rev. 2008, 108, 845-910. [CrossRef]

2. Chen, M.; Kumar, D.; Yi, C.-W.; Goodman, D.W. The promotional effect of gold in catalysis by palladium-gold. Science 2005, 310, 291-293. [CrossRef]

3. Yi, C.-W.; Luo, K.; Wei, T.; Goodman, D.W. The composition and structure of Pd-Au surfaces. J. Phys. Chem. B 2005, 109, 18535-18540. [CrossRef]

4. McCue, A.J.; Anderson, J.A. CO induced surface segregation as a means of improving surface composition and enhancing performance of CuPd bimetallic catalysts. J. Catal. 2015, 329, 538-546. [CrossRef]

5. Meyer, R.J.; Zhang, Q.; Kryczka, A.; Gomez, C.; Todorovic, R. Perturbation of reactivity with geometry: How far can we go? ACS Catal. 2018, 8, 566-570. [CrossRef]

6. Smirnova, N.S.; Markov, P.V.; Baeva, G.N.; Rassolov, A.V.; Mashkovsky, I.S.; Bukhtiyarov, A.V.; Prosvirin, I.P.; Panafidin, M.A.; Zubavichus, Y.V.; Bukhtiyarov, V.I.; et al. CO-induced segregation as an efficient tool to control the surface composition and catalytic performance of $\mathrm{PdAg}_{3} / \mathrm{Al}_{2} \mathrm{O}_{3}$ catalyst. Mendeleev Commun. 2019, 29, 547-549. [CrossRef]

7. Reocreux, R.; Uhlman, M.B.; Thuening, T.; Kress, P.L.; Hannagan, R.T.; Stamatakis, M.; Sykes, E.C.H. Efficient and selective carbon-carbon coupling on coke-resistant PdAu single-atom alloys. Chem. Commun. 2019, 55, 15085. [CrossRef]

8. Liu, L.; Corma, A. Metal catalysts for heterogeneous catalysis: From single atoms to nanoclusters and nanoparticles. Chem. Rev. 2018, 118, 4981-5079. [CrossRef] [PubMed]

9. Li, L.; Chang, X.; Lin, X.; Zhao, Z.-J.; Gong, J. Theoretical insights into single-atom catalysts. Chem. Soc. Rev. 2020, 49, 8156-8178. [CrossRef]

10. Sykes, E.C.H.; Christopher, P. Recent advances in single-atom catalysts and single-atom alloys: Opportunities for exploring the uncharted phase space in-between. Current Opin. Chem. Eng. 2020, 29, 67-73. [CrossRef]

11. Hannagan, R.T.; Giannakakis, G.; Flytzani-Stephanopoulos, M.; Sykes, E.C.H. Single-atom alloy catalysis. Chem. Rev. 2020, 120, 12044-12088. [CrossRef] [PubMed]

12. Calvo, F. Thermodynamics of nanoalloys. Phys. Chem. Chem. Phys. 2015, 17, 27922-27939. [CrossRef] [PubMed]

13. Bukhtiyarov, A.V.; Prosvirin, I.P.; Saraev, A.A.; Klyushin, A.Y.; Knop-Gericke, A.; Bukhtiyarov, V.I. In situ formation of the active sites in Pd-Au bimetallic nanocatalysts for CO Oxidation: NAP (Near Ambient Pressure) XPS and MS study. Faraday Discuss. 2018, 208, 255-268. [CrossRef] [PubMed]

14. Mamatkulov, M.; Yudanov, I.V.; Bukhtiyarov, A.V.; Prosvirin, I.P.; Bukhtiyarov, V.I.; Neyman, K.M. Pd segregation on the surface of bimetallic PdAu nanoparticles induced by low coverage of adsorbed CO. J. Phys. Chem. C 2019, 123, 8037-8046. [CrossRef] 
15. Wolfbeisser, A.; Kovács, G.; Kozlov, S.M.; Föttinger, K.; Bernardi, J.; Klötzer, B.; Neyman, K.M.; Rupprechter, G. Surface composition changes of $\mathrm{CuNi}-\mathrm{ZrO}_{2}$ during methane decomposition: An operando NAP-XPS and Density Functional study. Catal. Today 2017, 283, 134-143. [CrossRef]

16. Verga, L.G.; Skylaris, C.K. DFT modeling of metallic nanoparticles. In Computational Modelling of Nanoparticles, Series: Frontiers of Nanoscience; Bromley, S.T., Woodley, S.M., Eds.; Elsevier: Oxford, UK, 2019; Volume 12. [CrossRef]

17. Soini, T.M.; Rösch, N. Size-dependent properties of transition metal clusters: From molecules to crystals and surfacesComputational studies with the program PARAGAUSS. Phys. Chem. Chem. Phys. 2015, 17, 28463-28483. [CrossRef]

18. Yudanov, I.V.; Genest, A.; Schauermann, S.; Freund, H.-J.; Rösch, N. Size-dependence of the adsorption energy of CO on metal nanoparticles: A DFT search for the minimum value. Nano Lett. 2012, 12, 2134-2139. [CrossRef]

19. Marchal, R.; Genest, A.; Krüger, S.; Rösch, N. Structure of Pd/Au alloy nanoparticles from a Density Functional Theory-based embedded-atom potential. J. Phys. Chem. C 2013, 117, 21810-21822. [CrossRef]

20. Kozlov, S.M.; Kovács, G.; Ferrando, R.; Neyman, K.M. How to determine accurate chemical ordering in several nanometer large bimetallic crystallites from electronic structure calculations. Chem. Sci. 2015, 6, 3868-3880. [CrossRef]

21. Kovács, G.; Kozlov, S.M.; Neyman, K.M. Versatile optimization of chemical ordering in bimetallic nanoparticles. J. Phys. Chem. C 2017, 121, 10803-10808. [CrossRef]

22. Atanasov, I.; Hou, M. Equilibrium ordering properties of Au-Pd alloys and nanoalloys. Surf. Sci. 2009, 603, 2639-2651. [CrossRef]

23. Yudanov, I.V.; Neyman, K.M. Stabilization of Au at edges of bimetallic PdAu nanocrystallites. Phys. Chem. Chem. Phys. 2010, 12, 5094-5100. [CrossRef] [PubMed]

24. Timoshenko, J.; Wrasman, C.J.; Luneau, M.; Shirman, T.; Cargnello, M.; Bare, S.R.; Aizenberg, J.; Friend, C.M.; Frenkel, A.I. Probing atomic distributions in mono- and bimetallic nanoparticles by supervised machine learning. Nano Lett. 2019, 19, 520-529. [CrossRef] [PubMed]

25. Bruma, A.; Ismail, R.; Paz-Borbón, L.O.; Arslan, H.; Barcaro, G.; Fortunelli, A.; Li, Z.Y.; Johnston, R.L. DFT study of the structures and energetics of 98-atom AuPd clusters. Nanoscale 2013, 5, 646-652. [CrossRef] [PubMed]

26. Rahm, J.M.; Erhart, P. Understanding chemical ordering in bimetallic nanoparticles from atomic-scale simulations: The competition between bulk, surface, and strain. J. Phys. Chem. C 2018, 122, 28439-28445. [CrossRef]

27. Kresse, G.; Furthmüller, J. Efficient iterative schemes for ab initio total-energy calculations using a plane-wave basis set. Phys. Rev. B 1996, 54, 11169-11186. [CrossRef]

28. Kresse, G.; Hafner, J. Ab initio molecular-dynamics simulation of the liquid-metal-amorphous-semicon-ductor transition in germanium. Phys. Rev. B 1994, 49, 14251-14269. [CrossRef]

29. Blöchl, P.E. Projector Augmented-Wave method. Phys. Rev. B 1994, 50, 17953-17979. [CrossRef]

30. Kresse, G.; Joubert, D. From ultrasoft pseudopotentials to the Projector Augmented-Wave method. Phys. Rev. B 1999, 59, 1758-1775. [CrossRef]

31. Perdew, J.P.; Burke, K.; Ernzerhof, M. Generalized Gradient Approximation made simple. Phys. Rev. Lett. 1996, 77, 3865-3868. [CrossRef]

32. Perdew, J.P.; Burke, K.; Ernzerhof, M. Generalized Gradient Approximation made simple. Phys. Rev. Lett. 1997, $78,1396$. [CrossRef]

33. Viñes, F.; Illas, F.; Neyman, K.M. On the mechanism of formation of metal nanowires by self-assembly. Angew. Chem. Int. Ed. 2007, 46, 7094-7097. [CrossRef] [PubMed]

34. Kozlov, S.M.; Aleksandrov, H.A.; Goniakowski, J.; Neyman, K.M. Effect of $\mathrm{MgO}(100)$ support on structure and properties of Pd and Pt nanoparticles with 49-155 Atoms. J. Chem. Phys. 2013, 139, 084701. [CrossRef] [PubMed]

35. Yudanov, I.V.; Sahnoun, R.; Neyman, K.M.; Rösch, N. Carbon monoxide adsorption on palladium nano-par-ticles: A relativistic density functional study. J. Chem. Phys. 2002, 117, 9887-9896. [CrossRef]

36. Yudanov, I.V.; Sahnoun, R.; Neyman, K.M.; Rösch, N.; Hoffmann, J.; Schauermann, S.; Johánek, V.; Unterhalt, H.; Rupprechter, G.; Libuda, J.; et al. CO adsorption on Pd nanoparticles: Density functional and vibrational spectroscopy studies. J. Phys. Chem. $B$ 2003, 107, 255-264. [CrossRef]

37. Neyman, K.M.; Sahnoun, R.; Inntam, C.; Hengrasmee, S.; Rösch, N. Computational study of model Pd-Zn nanoclusters and their adsorption complexes with CO molecules. J. Phys. Chem. B 2004, 108, 5424-5430. [CrossRef]

38. Laletina, S.S.; Mamatkulov, M.; Shor, E.A.; Kaichev, V.V.; Genest, A.; Yudanov, I.V.; Rösch, N. Size-dependence of the adsorption energy of CO on Pt nanoparticles: Tracing two intersecting trends by DFT calculations. J. Phys. Chem. C 2017, 121, 17371-17377. [CrossRef]

39. Kovács, G.; Kozlov, S.M.; Matolínová, I.; Vorokhta, M.; Matolín, V.; Neyman, K.M. Revealing chemical ordering in Pt-Co nanoparticles using electronic structure calculations and X-Ray photoelectron spectroscopy. Phys. Chem. Chem. Phys. 2015, 17, 28298-28310. [CrossRef]

40. Vorokhta, M.; Khalakhan, I.; Václavů, M.; Kovács, G.; Kozlov, S.M.; Kúš, P.; Skála, T.; Tsud, N.; Lavková, J.; Potin, V.; et al. Surface composition of magnetron sputtered Pt-Co thin film catalyst for proton exchange membrane fuel cells. Appl. Surf. Sci. 2016, 365, 245-251. [CrossRef]

41. Neitzel, A.; Kovács, G.; Lykhach, Y.; Kozlov, S.M.; Tsud, N.; Skála, T.; Vorokhta, M.; Matolín, V.; Neyman, K.M.; Libuda, J. Atomic ordering and $\mathrm{Sn}$ segregation in Pt-Sn nanoalloys supported on $\mathrm{CeO}_{2}$ thin films. Top. Catal. 2017, 60, 522-532. [CrossRef] 
42. Khalakhan, I.; Vega, L.; Vorokhta, M.; Skála, T.; Viñes, F.; Yakovlev, Y.V.; Neyman, K.M.; Matolínová, I. Irreversible structural dynamics on the surface of bimetallic PtNi alloy catalyst under alternating oxidizing and reducing environments. Appl. Catal. B Envir. 2020, 264, 118476. [CrossRef]

43. Olobardi, S.; Vega, L.; Fortunelli, A.; Stener, M.; Viñes, F.; Neyman, K.M. Optical properties and chemical ordering of Ag-Pt nanoalloys: A computational study. J. Phys. Chem. C 2019, 123, 25482-25491. [CrossRef]

44. Vega, L.; Aleksandrov, H.A.; Neyman, K.M. Using density functional calculations to elucidate atomic ordering of Pd-Rh nanoparticles at sizes relevant for catalytic applications. Chin. J. Catal. 2019, 40, 1749-1757. [CrossRef]

45. Rahm, J.M. Thermodynamics and Optical Response of Palladium-Gold Nanoparticles. Master's Thesis, Department of Physics, Chalmers University of Technology, Gothenburg, Sweden, 2016.

46. Nelayah, J.; Nguyen, N.T.; Alloyeau, D.; Wang, G.Y.; Ricolleau, C. Long-range chemical orders in Au-Pd nanoparticles revealed by aberration-corrected electron microscopy. Nanoscale 2014, 6, 10423-10430. [CrossRef] [PubMed]

47. Sluiter, M.H.F.; Colinet, C.; Pasturel, A. Ab initio calculation of the phase stability in Au-Pd and Ag-Pt alloys. Phys. Rev. B 2006, 73, 174204. [CrossRef]

48. Gao, F.; Wang, Y.L.; Goodman, D.W. CO oxidation over AuPd(100) from ultrahigh vacuum to near-atmospheric pressures: The critical role of contiguous Pd atoms. J. Am. Chem. Soc. 2009, 131, 5734-5735. [CrossRef]

49. Sitja, G.; Henry, C.R. Molecular beam study of the CO adsorption on a regular array of PdAu clusters on alumina. J. Phys. Chem. C 2019, 123, 7961-7967. [CrossRef]

50. Zhu, X.; Guo, Q.; Sun, Y.; Chen, S.; Wan, J.-Q.; Wu, M.; Fu, W.; Tang, Y.; Duan, X.; Chen, D.; et al. Optimising surface $d$ charge of AuPd nanoalloy catalysts for enhanced catalytic activity. Nat. Commun. 2019, 10, 1428. [CrossRef]

51. Bukhtiyarov, A.V.; Burueva, D.B.; Prosvirin, I.P.; Klyushin, A.Y.; Panafidin, M.A.; Kovtunov, K.V.; Bukhtiyarov, V.I.; Koptyug, I.V. Bimetallic $\mathrm{Pd}-\mathrm{Au} /$ highly oriented pyrolytic graphite catalysts: From composition to pairwise parahydrogen addition selectivity. J. Phys. Chem. C 2018, 122, 18588-18595. [CrossRef] 